\title{
EVALUATION AND DETERMINATION OF TRAMADOL AND METHADONE IN VITREOUS SAMPLES WITH THE AID OF DISPERSIVE LIQUID-LIQUID MICROEXTRACTION- HIGH PERFORMANCE LIQUID CHROMATOGRAPHY
}

\author{
DARUISH BADAKHSHAN ${ }^{a}$, MAJID RAMEZANI ${ }^{a^{*}}$ \\ ${ }^{a}$ Department of Chemistry, Faculty of Science, Arak Branch, Islamic Azad University, Arak, Iran.
}

\begin{abstract}
In the present work, the use of microextraction methods for the separation and pre-concentration of narcotic drugs in urine and vitreous samples is presented. These simple and eco-friendly methods are used to measure tramadol and methadone, which are used to relieve pain and treat addiction to other drugs. Urine and vitreous samples from 54 corpses referenced to legal medicine were analyzed by high performance liquid chromatography. Extraction of tramadol and methadone was performed separately using $200 \mu \mathrm{l}$ chloroform, $700 \mu \mathrm{l}$ methanol at $\mathrm{pH} 10$. Under the optimum conditions, the detection limit linear range were obtained $4.5 \mu \mathrm{g} \mathrm{\textrm {L } ^ { - 1 }}$ and $1.2 \mu \mathrm{g} \mathrm{L}^{-1}, 4.5-1000 \mu \mathrm{g} \mathrm{L}^{-1}$ and 1-1000 $\mu \mathrm{g} \mathrm{L}^{-1}$ for determination of tramadol and methadone, respectively. According to the results, for accurate interpretation of the methadone and tramadol concentration in the bodies, its measurement in vitreous fluid is very useful and practical.
\end{abstract}

Keywords: Tramadol, Methadone, Dispersive liquid - liquid microextraction, High performance liquid chromatography.

\section{INTRODUCTION}

In recent years, many efforts have been made to devise new methods for measuring trace amounts of analytes in different samples and remarkable progress has been made in this regard. Due to the low concentration of analytes and the complex tissue of the sample, preparation step before measurement is necessary. Sample preparation involves transforming the actual sample tissue into a state suitable for analysis by separation technique or other methods [1]. Sample statistics are generally considered to be the most time consuming analytical step and can be a major source of low accuracy and precision.

The basic stage of sample preparation is the extraction process used to separate and pre-concentrate the trace amounts of analyte from the sample tissue (solid, liquid, gas). The ideal extraction method is a rapid, simple, repeatable and inexpensive method; the quantitative retrieval of the species can be achieved without losing or destroying them; take a low sample size; has a high degree of selectivity and minimizes the use of solvent. Ultimately, there is no need to concentrate and reduce the volume of the extraction phase. On this basis, many methods have been considered in recent years [2].

As stated, the most important part of many chromatographic analyzes of biological samples is the removal of annoying agents in the sample. Also, for sample injection into HPLC, the increase of analyte concentration per sample unit is one of the necessities of the analytical process. Sample preparation before analysis to determine the amount of methadone (MD) and tramadol (TRM) in different samples is inevitable. In previous studies, the extraction of liquid-liquid extraction (LLE) and solid phase extraction (SPE) have been used to prepare methadone and tramadol in different samples [3-6]. Despite the common use of SPE and LLE, each of these methods has some disadvantages.

Disadvantages of LLE are time consuming, high cost and high volumes of sample and toxic organic solvents[7]. As an alternative method, dispersive liquid - liquid micro extraction (DLLME) can be used, which has been dramatically improved in recent years. This technique was presented in 2006 by Asadi et al [8] based on the triple solvent system [9], which is very low cost, simple and fast [10]. Another benefit of this method is high enrichment factor. This method involves an organic extraction solvent, a dispersive solvent (which must have the ability to disperse in both the aqueous and organic phases) and the aqueous solution of the sample [11]. So far, many applications of this method have been reported in various fields [12-14].

Determination of drugs in biological samples is mainly for the purpose of studying and evaluating their residual levels in the body [15]. After taking the drugs, they do not completely excrete the body and remain in various tissues. Knowing the amount of drug remaining in the human body is led to infer the appropriate dose. Another important factor in measuring drugs is the side effects of the drug. As a result, studying the amount of drug in biological samples is done to maximize the positive effect and minimize the ill effects of the drug.
Reducing pain is one of the main goals in medical science to improve quality of life. Palliative drugs are compounds that increase the threshold of pain, and thus reduce pain without disturbing the level of consciousness or altering other emotions [16]. Methadone [17] (Figure 1) and tramadol [18] (Figure 2) are painreducing compounds that are used to reduce the pain of cancer patients, childbirth and post-surgical complications $[19,20]$.

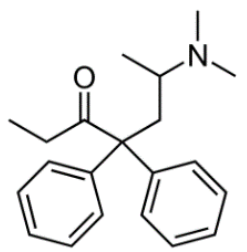

Figure 1. The chemical structure of methadone.

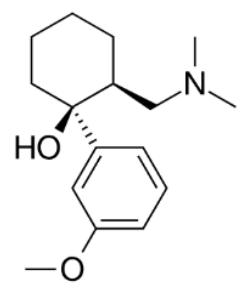

Figure 2. The chemical structure of tramadol.

These drugs belong to the opioid group. Methadone and tramadol are often used as inhibitors of heroin addiction and other narcotic drugs [21-24]. Consumption without prescribing these drugs causes seizures, liver failure, cardiovascular problems, and death. In order to evaluate the amount of tramadol and methadone in plasma and fluids in the body and its amount in pharmaceutical compounds, various methods are used [25]. Spectrophotometers [26, 27], HPLC [28-30], GC/MS [31, 32], HPTLC [33], LC-MS [34], LC-MS/MS [35-37], capillary electrophoresis $[38,39]$, and electrochemical methods $[40,41]$ can be mentioned.

Blood is still considered the first choice in the toxicological analysis, but it may not be available in many situations, or because corruption cannot be used for measurement. Therefore, the role and importance of other body environments will be further enhanced Vitreous toxicology analyzes have many benefits [42] Vitreous fluid due to simple sampling without the need for autopsy is one of the samples to be considered in forensic medicine and also after death [43], blood contamination and bacteria are relatively safe. Vitreous fluid is clear, which helps facilitate the testing. Also, vitreous has high chemical stability. The use of this sample has a long and valuable history in forensic medicine; especially in the diagnosis of drugs. The mechanism for the transfer of small molecules from blood into ocular fluids was studied in the mid-1940s .Since then, chemists have evaluated various types of drugs and biochemical compounds in the vitreous. 
The purpose of this paper was to optimize the methodology for determining the trace amounts of methadone and tramadol in urine and vitreous in the bodies of reference to the legal medicine that has high precision and accuracy and can be done in ordinary laboratories. For this purpose, the liquid-liquid microextraction method was investigated, because it has all the advantages mentioned.

\section{MATERIALS AND METHODS}

\section{Apparatus}

A high performance liquid chromatography (EuroChrom, KNAUER, and Germany) which consisted of K-1001 pumps, multiple solvent delivery unit, vacuum degasser and K-2600 Photodiode Array detector (KNAUER, Germany) was used for chromatographic analysis. Separations were performed on a C18 chromatography column (250 $\mathrm{mm} \times 4.6 \mathrm{~mm}$, particle diameter of $5 \mu \mathrm{m})$. The injection volume was $20 \mu \mathrm{l}$ and the column temperature was ambient temperature. The speed of the mobile phase was also $1 \mathrm{ml} / \mathrm{min}$. The $\mathrm{pH}$ of the solutions was adjusted with a pH meter (WTW Inolab model, Germany).

\section{Chemicals and reagents}

All the chemicals and reagent were of analytical grade. Methadone and tramadol were purchased from Sigma Aldrich. Ethanol, chloroform, methanol, acetone, acetonitrile and carbon tetrachloride were purchased from MERCK (Germany). To prepare the stocks solution of methadone and tramadol, an appropriate amount of them was weighed and distilled water was added to the volume. This solution can be stored at $4^{\circ} \mathrm{C}$ for 30 days. The solutions used during the experiment were prepared from the continuous dilution of Stoke solution daily. Sodium hydroxide solution and hydrochloric acid solution were used to adjust the $\mathrm{pH}$ of the solutions.

To prepare the mobile phase, phosphate buffer and acetonitrile with a ratio of $25: 75(\mathrm{pH}=2.38)$ were used to measure tramadol and a ratio of 32:68 $(\mathrm{pH}=2.38)$ to methadone

\section{Real sample preparation}

At first, the vitreous and urine samples were centrifuged at $3000 \mathrm{rpm}$ for 5 minutes and then filtered. In a centrifuge tube, $1 \mathrm{ml}$ of vitreous and urine samples were individually mixed with $10 \mathrm{ml}$ of distilled water, and the $\mathrm{pH}$ was adjusted to 10 with sodium hydroxide solution.

\section{DLLME procedure}

The general steps of performing sample preparation using the DLLME method are as follows. First, $600 \mu \mathrm{l}$ of mixture containing $100 \mu \mathrm{l}$ of chloroform (as an extraction solvent) and $500 \mu \mathrm{l}$ of methanol (as a dispersed solvent was added rapidly to $5 \mathrm{ml}$ of the aqueous sample that is placed in a centrifugal conical tube. As a result, a cloudy solution was occurred and the surface area between the extraction solvent and the aqueous sample is increased in the formation of the cloudy solution and the state of equilibrium is very rapid, which is the main advantage of this method. In order to transfer the analyte to the extraction solvent, the solution was shaken slowly for 2 minutes and centrifuged at $4500 \mathrm{rpm}$. In the next step, the chloroform (containing analytes) is separated from the bulk solution and settled at the bottom of the test tube. This phase was separated by a syringe and dried by the gentle stream of nitrogen gas. Then $20 \mu 1$ methanol added and sample was injected into HPLC.

\section{RESULTS AND DISCUSSION}

Due to low concentrations and the presence of other compounds in body fluids, determining the amount of methadone and tramadol is a serious challenge for analysts. These compounds can be measured in blood, urine and vitreous. Therefore, the use of extraction methods is applied. In order to obtain the best extraction efficiency, important experimental factors that can affect extraction (such as $\mathrm{pH}$, the type and volume of extraction solvent, type and volume disperser solvent, ionic strength and extraction time) were carefully considered. One-factor at a time was used to simplify the optimization steps. For this purpose, some experiments were designed. Following the enrichment factor and recovery are calculated using equations (1) and (2).
The enrichment factor $(\mathrm{EF})$ is described as the ratio of the concentration of the analyte in the settled phase $\left(\mathrm{C}_{\text {sed }}\right)$ to the initial concentration in the aqueous phase $\left(\mathrm{C}_{0}\right)$, which is shown in the equation (1):

$$
E F=C_{\text {sed }} / C_{0}
$$

Extraction recovery (ER) is defined as the percentage of the analyte amount in the extraction phase $\left(\mathrm{n}_{\mathrm{sed}}\right)$ to the initial amount of analyte in the sample $\left(\mathrm{n}_{0}\right)$ and can be calculated according to the following equation:

$$
E R=\frac{n_{\text {sed }}}{n_{0}} \times 100 \%=\frac{C_{\text {sed }} V_{\text {sed }}}{C_{0} V_{0}} \times 100 \%=E F \times \frac{V_{\text {sed }}}{V_{0}} \times 100 \%
$$

where $\mathrm{V}_{\text {sed }}$ and $\mathrm{V}_{0}$ are the volumes of sedimented phase and sample solution, respectively.

\section{Influence of extraction solvent type and volume}

Selection of solvent extraction is very important in the DLLME process. An appropriate extraction solvent for this method should have low solubility in water, a lower density of water, and the ability to extract the desired analytes. In addition, the low toxicity and the proper chromatographic behavior (i.e., the solvent marker does not overlap with the analyte, the solvent can easily be removed from the chromatographic column and the best separation of the components) are other desirable features for the extraction solvent. In this study, in order to obtain the appropriate extraction solvent, different solvents were studied under the same conditions. Chloroform, carbon tetrachloride and dichloroethane were chosen for better extraction efficiency and compared. The best extraction efficiency is when chloroform is used as extraction solvent. The low solubility of chloroform in water and the high distribution coefficient of the compounds in this solvent are also due to the higher recovery of this solvent than other solvents (Figure 3). To optimize the extraction solvent volume, different volumes of chloroform (100 to $300 \mu \mathrm{L})$ were investigated, while other laboratory factors were constant. The extraction efficiency when the volume of chloroform was $100 \mu \mathrm{L}$ reached the highest point and then decreased with increasing chloroform volume. Therefore, $100 \mu$ of chloroform was used for subsequent experiments.

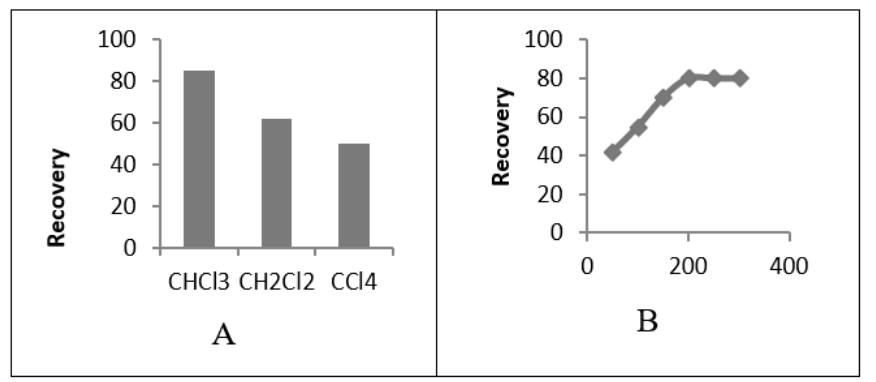

Figure 3. Effect of the type (A) and volume (B) extraction solvent on the recovery.

\section{Influence of disperser solvent type and volume}

Selection of disperser solvent is an important factor in the DLLME. The disperser solvent must have the ability to dissolve in both organic solvents and aqueous samples. Acetone, acetonitrile, ethanol and methanol were selected to optimize this factor. Figure 4 shows the effect of disperser solvent type on extraction efficiency. According to the results, the best extraction efficiency is obtained when methanol is used as disperser solvent. Therefore, subsequent studies were carried out using methanol as disperser solvent. In order to study the effect of disperser solvent volume on extraction efficiency, different volumes of methanol from 100 to $1000 \mu \mathrm{l}$ were studied. The highest extraction efficiency is obtained using $500 \mu \mathrm{l}$ methanol and then decreases with increasing methanol volume.

Because of increasing disperser solvent volume, the distribution of extraction solvent in aqueous sample is better done, which leads to increased extraction efficiency. On the other hand, when the volume of solvent disperser exceeds a certain limit, part of the extraction solvent in water is dissolved, and thus the extraction efficiency decreases. 


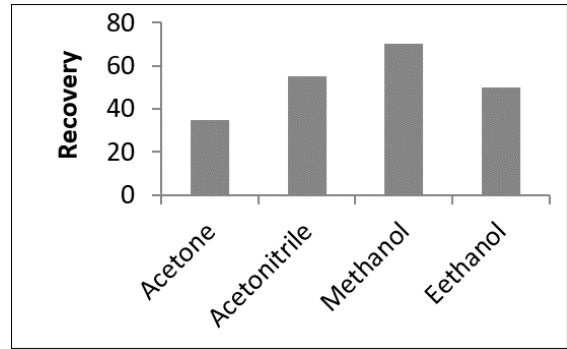

Figure 4. Effect of the type disperser solvent on the recovery.

\section{Influence of $\mathrm{pH}$ and ionic strength}

It is well known that the $\mathrm{pH}$ of solution is an important factor during liquidliquid extraction (LLE) process. In this method, the $\mathrm{pH}$ is adjusted so that the analyte remains mainly in the molecular form until it extract in the organic phase. Because the ionic form of a molecule that is obtained from the acceptance or donation of protons in acid or alkali cannot be transferred from the aqueous phase to the organic phase. In order to evaluate the effect of $\mathrm{pH}$ on the efficiency of the proposed microextraction method, the $\mathrm{pH}$ of the solution in the range of 2 to 12 was investigated. Figure 5 shows the analytical response to the $\mathrm{pH}$ of the solution. As seen in the figure, the best extraction efficiency was obtained at $\mathrm{pH} 10$.

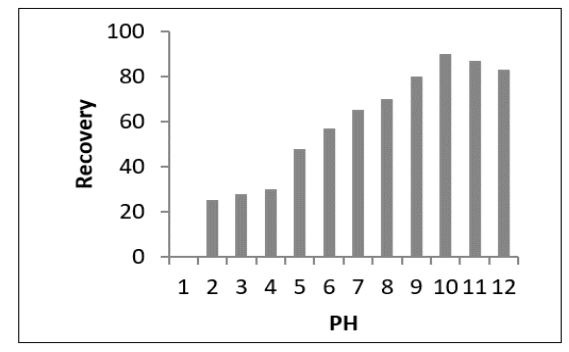

Figure 5. Effect of the $\mathrm{pH}$ on the recovery.

\section{Influence of microextraction time}

The extraction time in the DLLME is defined as the time between the injection of the extraction and disperser solvent to centrifugation. Extraction is performed immediately after the formation of a cloud solution. This time refers to the high contact level of the water phase and the organic phase. In this work, the time was measured from 2 to 10 minutes. According to the results, the extraction time was not affected and 2 minutes were considered as optimal amount .

\section{Analysis of real samples}

To evaluate the effectiveness of the proposed DLLME method, this method was used to measure methadone and tramadol in urine and vitreous (Figure 6). The results are summarized in Tables 1 and 2 . As it can be seen, good recovery of $96-98 \%$ indicates the negligible effect of sample tissue on the performance of the proposed DLLME method.

a)

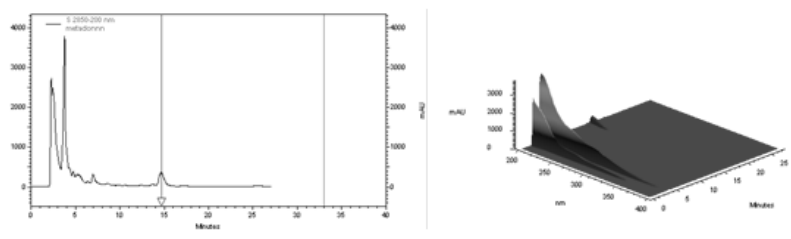

b)

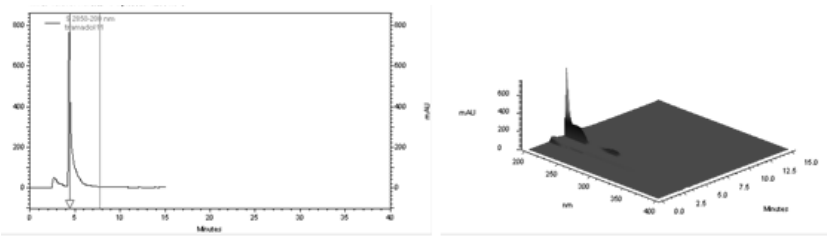

Figure 6. (a)Methadone spectrum (b) tramadol spectrum in the vitreous sample by HPLC.

\section{Figures of Merit}

The analytical parameters were measured under optimal conditions at $578 \mathrm{~nm}$. The calibration curve for methadone and tramadol were in the range of 4.5-1000 $\mu \mathrm{g} \mathrm{L}^{-1}$ linear. The detection limit of the relation $\mathrm{C}_{\mathrm{LOD}}=3 \mathrm{~S}_{\mathrm{b}} / \mathrm{m}$ is calculated $\left(\mathrm{C}_{\mathrm{LOD}}\right.$, $\mathrm{S}_{\mathrm{b}}, \mathrm{m}$, respectively, the detection limit, standard deviation, and calibration curve slope). The values $1.2 \mu \mathrm{g} \mathrm{L}^{-1}$ and $1.5 \mu \mathrm{g} \mathrm{L}^{-1}$ for methadone and tramadol were obtained. Relative standard deviation (RSD) for concentrations of $100 \mu \mathrm{g} \mathrm{L}^{-1}$ medications with six consecutive duplicates 4.5-6.7 (for TRM) and .4.5-7.1 (for MD) were obtained.

Table 1. Analytical characteristics of the method.

\begin{tabular}{|c|c|c|c|}
\hline \multirow{2}{*}{\multicolumn{2}{|c|}{ Parameter }} & \multicolumn{2}{|c|}{ Analytical feature } \\
\hline & & TRM & MD \\
\hline \multicolumn{2}{|l|}{ Linear range $\left(\mu \mathrm{g} \mathrm{L}^{-1}\right)$} & $1-1000$ & $1-1000$ \\
\hline \multicolumn{2}{|l|}{ Limit of detection $\left(\mu \mathrm{g} \mathrm{L}^{-1}\right)$} & 1.5 & 1.2 \\
\hline \multicolumn{2}{|l|}{ RSD\% (Inter-day, $\mathrm{n}=7$ ) } & $4.5-6.7$ & $4.5-7.1$ \\
\hline \multicolumn{2}{|l|}{ Regression equation } & $y=18.52 C+78.74$ & $\mathrm{y}=16.24 \mathrm{C}+109.01$ \\
\hline \multirow{2}{*}{ Enrichment factor } & Vitreous & 132 & 118 \\
\hline & Urine & 121 & 109 \\
\hline \multirow{2}{*}{ Extraction recovery $(\%)$} & Vitreous & 79 & 81 \\
\hline & \begin{tabular}{|l|} 
Urine \\
\end{tabular} & 72 & 77 \\
\hline
\end{tabular}

MD and TRM concentration were $100 \mu \mathrm{g} \mathrm{L}^{-1}$ for which RSD was obtained.

\section{Comparison with other methods}

Comparison of the method studied with other preconcentration methods is summarized in Table 2. Observations show that the dispersive liquid-liquid microextraction method has the higher enrichment factor, lower detection limit, lower solvent consumption, and shorter extraction time than other methods.

Table 2. Comparison of the parameters of the DLLME method with other methods.

\begin{tabular}{|c|c|c|c|c|c|}
\hline Method & Analyte & $\begin{array}{c}\text { LOD } \\
\left(\mu \mathrm{g} \mathrm{L}^{-1}\right)\end{array}$ & $\begin{array}{c}\mathbf{L R}^{\mathbf{b}} \\
\left(\mu \mathrm{g} \mathbf{L}^{-1}\right)\end{array}$ & $\begin{array}{l}\text { RSD } \\
(\%)\end{array}$ & Ref. \\
\hline SHS-HLLME-GC-FID & $\begin{array}{l}\text { TRM } \\
\text { MD }\end{array}$ & $\begin{array}{l}1.2 \\
1.2\end{array}$ & $\begin{array}{l}4-1000 \\
4-1000\end{array}$ & $\mid$\begin{tabular}{|}
$5.6-7.6$ \\
$5.6-7.1$
\end{tabular} & [44] \\
\hline $\mathrm{SPE}^{\mathrm{d}}-\mathrm{GC}-\mathrm{MS}$ & TRM & 10 & $100-20000$ & $4.7-7.9$ & {$[45]$} \\
\hline HS-SPME-GC-MS & TRM & 0.2 & $1-400$ & 4.8 & {$[46]$} \\
\hline DES-AAELLME ${ }^{\mathrm{f}}-$ GCFID & MD & 0.7 & $2-8000$ & 5.4 & {$[47]$} \\
\hline DLLME- HPLC-DAD & $\begin{array}{l}\text { TRM } \\
\text { MD }\end{array}$ & $\begin{array}{l}1.5 \\
1.2\end{array}$ & $\begin{array}{l}1-1000 \\
1-1000\end{array}$ & \begin{tabular}{|}
$4.5-6.7$ \\
$4.5-7.1$
\end{tabular} & $\begin{array}{l}\text { This } \\
\text { work }\end{array}$ \\
\hline
\end{tabular}

${ }^{\mathrm{b}}$ Linear range.

${ }^{\mathrm{d} S}$ Solid-phase extraction.

fDeep eutectic solvent air assisted emulsification liquid-liquid microextraction method.

${ }^{g}$ Dispersive liquid-liquid microextraction based on the solidification of a floating organic droplet.

\section{CONCLUSION}

Efforts to measure faster, easier, and less costly pharmaceutical drugs and related compounds in various drug samples, such as pills and capsules, and biological samples, many researchers have been working worldwide. In terms of measuring the amount of drug, biological samples in addition to the need to have the expertise and the equipment for sample preparation are also more sensitive in place. Hence, methods that can measure low drug levels in biological samples, as well as less environmental hazards, are prioritized.

Therefore, the importance of measuring narcotic drugs due to the effects of these drugs on the health of society is very high. In this research, dispersive liquid-liquid micro-extraction method using liquid chromatography was successfully used to measure tramadol and methadone in the vitreous and urine samples. The benefits of this approach are low cost sampling, less biocontamination than the methods used to measure biological fluids. 


\section{REFERENCE}

1. L. Ramos, J. Chromatogr. A 1221, 84-98, (2012).

2. J. Pawliszyn and S. Pedersen-Bjergaard, J. Chromatogr. Sci. 44, 291-307, (2006).

3. Y.-F. Cheng, U. D. Neue and L. L. Woods, J. Chromatogr. B: Biomed. Sci. Appl. 729, 19-31, (1999).

4. M. E. Rodriguez-Rosas, J. G. Medrano, D. H. Epstein, E. T. Moolchan, K. L. Preston and I. W. Wainer, J. Chromatogr. A 1073, 237-248, (2005).

5. P. Fernandez, L. Morales, C. Vazquez, A. Bermejo and M. J. Tabernero, Forensic Sci. Int. 161, 31-35, (2006).

6. L. Mercolini, R. Mandrioli, M. Conti, C. Leonardi, G. Gerra and M. A. Raggi, J. Chromatogr. B 847, 95-102, (2007).

7. E. Psillakis and N. Kalogerakis, TrAC, Trends Anal. Chem. 22, 565-574, (2003).

8. M. Rezaee, Y. Assadi, M.-R. M. Hosseini, E. Aghaee, F. Ahmadi and S. Berijani, J. Chromatogr. A 1116, 1-9, (2006).

9. J. M. Kokosa, TrAC, Trends Anal. Chem. 43, 2-13, (2013).

10. V. Andruch, I. S. Balogh, L. Kocúrová and J. Šandrejová, Appl. Spectrosc. Rev. 48, 161-259, (2013).

11. A. V. Herrera-Herrera, J. Hernández-Borges, T. M. Borges-Miquel and M. Á. Rodríguez-Delgado, Electrophoresis 31, 3457-3465, (2010).

12. A. Farahani, M. Ramezani and J. Hassan, Sep. Sci. Technol. 52, 1505-1511, (2017).

13. E. Koosha, M. Ramezani and A. Niazi, Int. J. Environ. Anal. Chem. 1-14, (2018).

14. L. Mousavi, Z. Tamiji and M. R. Khoshayand, Talanta, (2018).

15. D. Han and K. H. Row, Microchim. Acta 176, 1-22, (2012).

16. A. Verdejo, I. Toribio, C. Orozco, K. L. Puente and M. Pérez-García, Drug Alcohol Depend. 78, 283-288, (2005).

17. V. P. Dole and M. E. Nyswander, JAMA 235, 2117-2119, (1976).

18. P. Dayer, J. Desmeules and L. Collart, Drugs 53, 18-24, (1997).

19. K. A. Harris Jr, J. H. Arnsten, H. Joseph, J. Hecht, I. Marion, P. Juliana and M. N. Gourevitch, J. Subst. Abuse Treat. 31, 433-438, (2006).

20. M. J. Kreek, K. S. LaForge and E. Butelman, Nat. Rev. Drug Discov. 1, 710, (2002).

21. J. E. Zweben and J. T. Payte, West. J. Med. 152, 588, (1990).

22. J. R. Cooper, JAMA 267, 281-282, (1992).

23. G. B. Colini and M. Cobianchi, Minerva Med. 103, 177-182, (2012).

24. F.-S. Lin, W.-Y. Lin, C.-H. Lai, C.-Y. Chen, C.-P. Lin, T.-F. Lin and W.-Z. Sun, Acta Anaesthesiol. Taiwan 50, 49-53, (2012).

25. K. Wolff, M. Sanderson, A. Hay and D. Raistrick, Clin. Chem. 37, 205-209, (1991).

26. R. Shukla, R. Shivkumar and K. N. Shivan, Bull. Pharm. Res 1, 62-66, (2011).

27. A. Kucuk and Y. Kadioglu, Asian J. Chem. 23, 663, (2011).

28. P. Fernández, S. Seoane, C. Vázquez, M. J. Tabernero, A. M. Carro and R. A. Lorenzo, J. Appl. Toxicol. 33, 740-745, (2013).

29. M. Javanbakht, M. M. Moein and B. Akbari-adergani, J. Chromatogr. B 911, 49-54, (2012).

30. G. Saccomanni, S. Del Carlo, M. Giorgi, C. Manera, A. Saba and M. Macchia, J. Pharm. Biomed. Anal. 53, 194-199, (2010).

31. P.-S. Cheng, C.-H. Lee, C. Liu and C.-S. Chien, J. Anal. Toxicol. 32, 253259, (2008).

32. E. Ghasemi, J. Chromatogr. A 1251, 48-53, (2012).

33. W. S. Solomon, P. V. Anand, R. Shukla, R. Sivakumar and R. Venkatnarayanan, Int. J. Chem Tech. Res 2, 2, (2010).

34. F. Musshoff, B. Madea, F. Stuber and U. M. Stamer, J. Anal. Toxicol. 30, 463-467, (2006).

35. F. Musshoff, J. Trafkowski, U. Kuepper and B. Madea, J. Mass Spectrom. 41, 633-640, (2006).

36. P. Verri, C. Rustichelli, F. Palazzoli, D. Vandelli, F. Marchesi, A. Ferrari and M. Licata, J. Pharm. Biomed. Anal. 102, 450-458, (2015).

37. N. V. De Moraes, G. R. Lauretti, M. N. Napolitano, N. R. Santos, A. L. P. C. Godoy and V. L. Lanchote, J. Chromatogr. B 880, 140-147, (2012).

38. L. F. Martins, M. Yegles and R. Wennig, J. Chromatogr. B 862, 79-85, (2008).

39. J. Li and H. Ju, Electrophoresis 27, 3467-3474, (2006).

40. M. Amiri-Aref, J. B. Raoof and R. Ojani, Colloids Surf. B. Biointerfaces 109, 287-293, (2013).

41. E. Garrido, J. Garrido, F. Borges and C. Delerue-Matos, J. Pharm. Biomed. Anal. 32, 975-981, (2003).

42. N. Baniak, G. Campos-Baniak, A. Mulla and J. Kalra, J Clin Exp Pathol 4, $1-7,(2015)$.

43. K. R. Ziminski, C. T. Wemyss, J. H. Bidanset, T. J. Manning and L. Lukash, J. Forensic Sci. 29, 903-909, (1984).
44. H. Ahmar, M. Nejati-Yazdinejad, M. Najafi and K. S. Hasheminasab, Chromatographia 1-8, (2018).

45. L. Chytil, M. Štícha, O. Matoušková, F. Perlík and O. Slanař, J. Chromatogr. B 877, 1937-1942, (2009).

46. Y. Sha, S. Shen and G. Duan, J. Pharm. Biomed. Anal. 37, 143-147, (2005).

47. N. Lamei, M. Ezoddin, K. Abdi, Talanta 165, 176-181, (2017). 